\title{
REVIEW
}

\section{Guidelines for allergic rhinitis need to be used in primary care}

\section{David J Costa ${ }^{a}$, Philippe J Bousquet ${ }^{\mathrm{b}, \mathrm{h}}$, Dermot Ryan ${ }^{\mathrm{c}}$, David Price ${ }^{\mathrm{d}}$, Pascal Demoly ${ }^{\mathrm{e}, \mathrm{h}}$, Jan Brozek ${ }^{\mathrm{fh}}$, Holger J Schünemann ${ }^{\mathrm{fh},}$, *Jean Bousquet ${ }^{\mathrm{g}, \mathrm{h}}$}

a Département de Médecine Générale, Université de Montpellier-Nimes, France

b Département d'Epidémiologie Clinique, Biostatistique, Santé Publique et Information Médicale, Groupe Hospitalo-Universtaire Carémeau, Nîmes, France

Woodbrook Medical Centre, Loughborough, UK; Department of General Practice and Primary Care, University of Aberdeen

d GPIAG Professor of Primary Care Respiratory Medicine, Department of General Practice and Primary Care, University of Aberdeen, Foresterhill Health Centre, Aberdeen UK

e Service des Maladies Respiratoires, Hôpital Arnaud de Villeneuve, Montpellier, France and INSERM U657

f McMaster University, Hamilton, Ontario, Canada

g Service des Maladies Respiratoires, Hôpital Arnaud de Villeneuve, Montpellier, France and INSERM UMR780

h Members of GA2LEN (Global Allergy and Asthma European Network), supported by the Sixth EU Framework program for research, contract nFOOD-CT-2004-506378

Received 6th January 2009; revised version received 27th April 2009; accepted 27th April 2009; online 9th June 2009

\begin{abstract}
Clinical Practice Guidelines for allergic rhinitis have been developed over the past 15 years and have been found to improve the care for patients with allergic rhinitis. The ARIA (allergic rhinitis and its impact on asthma) guideline was the first of these evidenced-based guidelines, developed with primary care physicians. Subsequent guidelines include those by the IPCRG, BSACI, the AAAAI/ACAAI Practice Parameters for the diagnosis and management of rhinitis, and the ARIA 2008 Update. These guidelines were based on various evidencebased models, but the first to use GRADE methodology (Grading of Recommendations Assessment, Development and Evaluation) is the ARIA 2009 Revision. Since primary care physicians treat the majority of patients with allergic rhinitis it is essential that they are involved in the development and implementation of guidelines for allergic rhinitis. Prior to their implementation, guidelines should be evaluated for their accuracy and user friendliness - specifically for primary care physicians - but such validation is rarely performed. This is of great importance, in particular as regards evaluating the applicability of evidence from high quality randomised controlled trials (RCTs) which are often based on highly selected patients not representing the population of patients seen in day-to-day practice.

(C) 2009 General Practice Airways Group. All rights reserved.

DJ Costa et al. Prim Care Resp J 2009; 18(4): 250-257

doi:10.4104/pcrj.2009.00028
\end{abstract}

Keywords allergic rhinitis, primary care, guideline, guideline evolution, methodology, ARIA, implementation

\section{Contents}

Abstract

Introduction

Evolution of concepts in guideline development

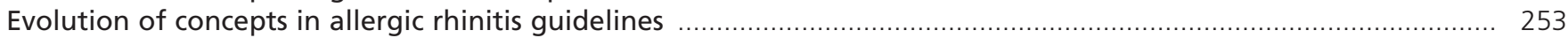

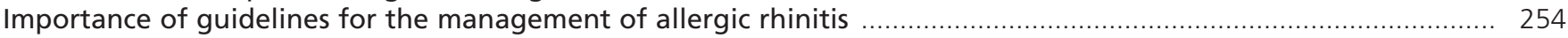

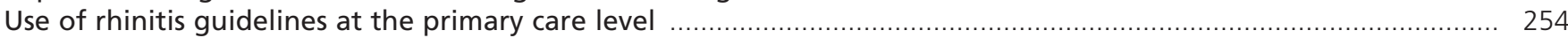

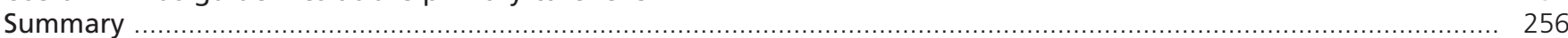

\footnotetext{
* Corresponding author: Professor Jean Bousquet, Service des Maladies Respiratoires, Hôpital Arnaud de Villeneuve, 371 avenue Doyen Gaston Giraud, 34275 Montpellier Cedex 5, France. Tel +33-467-41-67-00 Fax +33-467-41-67-01 E-mail: jean.bousquet@inserm.fr
} 


\section{Introduction}

Allergic rhinitis represents a global health problem. It is a common disease worldwide affecting up to $40 \%$ of the population in young adults and its prevalence is increasing. ${ }^{1}$ Although allergic rhinitis is not usually a severe disease, it alters the social life of patients, and affects school performance and work productivity., ${ }^{2,3}$ Moreover, the costs incurred by rhinitis are substantial. Asthma and rhinitis are common co-morbidities suggesting the concept of "one airway, one disease".

Clinical Practice Guidelines for allergic rhinitis have been developed over the past 15 years ${ }^{4-6}$ and have been found to improve care for patients with allergic rhinitis. ${ }^{7}$ ARIA (allergic rhinitis and its impact on asthma) was the first evidencedbased guideline. ${ }^{8}$ It was developed with primary care physicians. Newer guidelines have been developed ${ }^{2,9-11}$ based on various evidence-based models, but the first using GRADE methodology ${ }^{12}$ is the ARIA 2009 Revision. ${ }^{12 a}$

Primary care physicians treat the majority of patients with allergic rhinitis ${ }^{13,14}$ and it is essential that they are involved in the development and implementation of guidelines for allergic rhinitis.

\section{Evolution of concepts in guideline development}

The development of clinical guidelines follows strict processes. ${ }^{15}$ Early guidelines were predominantly derived from unsystematically-compiled opinions of experts based on clinical trials and mechanistic approaches (Opinion-based medicine). ${ }^{16}$ "Evidence-based medicine" (EBM) has become an essential component in the preparation of guidelines. It is the ability to track down, appraise critically (for its validity and usefulness) and incorporate the information obtained from the best available evidence (ideally randomised controlled trials, RCTs, but the emphasis is on "best") in order to establish the clinical basis for diagnosis, prognosis and therapeutics. ${ }^{17,18} \mathrm{~A}$ systematic evaluation of the available evidence has now become an essential component in the preparation of guidelines, which are an integral component of EBM defined as "the conscientious, explicit, and judicious use of current best evidence in making decisions about the care of individual patients" ${ }^{19}$ It requires a bottom-up approach that integrates the best external evidence with individual clinical expertise and patient choice. Evidence-based medicine attempts to provide a logical and convenient framework from which the quality and relevance of clinical studies may be assessed in an unbiased manner. ${ }^{20}$ Systematic reviews contribute to resolving uncertainty when original research, reviews and editorials disagree. ${ }^{21}$ The Cochrane Collaboration has led the way in setting new standards for the preparation of systematic reviews ${ }^{22}$ despite existing criticism. ${ }^{23,24}$
Figure 1. Development of a guideline.

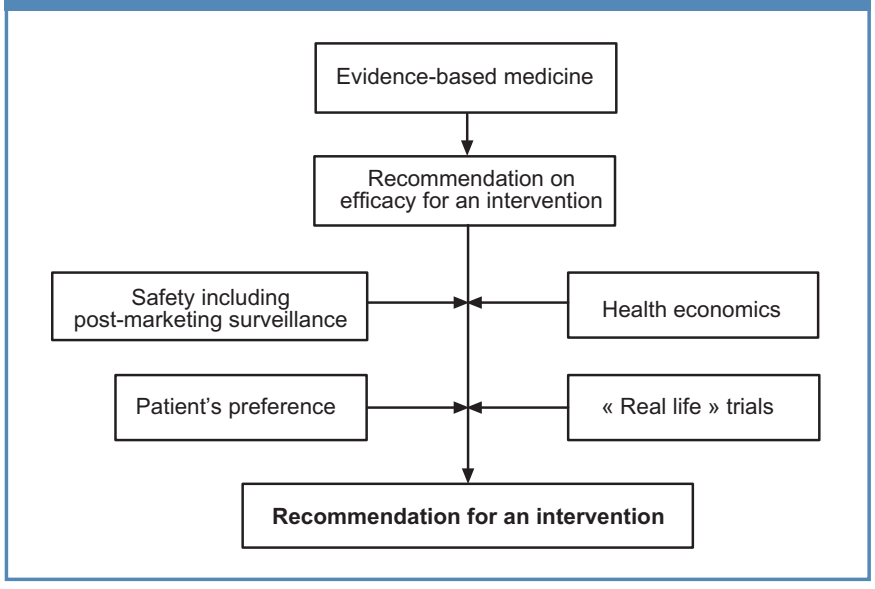

While there is increasing agreement on the components of proper clinical practice guidelines and what constitutes high quality evidence, it is also clear that the highest quality evidence from RCTs is often based on selected patients. Therefore, RCTs may fall short of representing the entire population. ${ }^{25}$ Nonetheless, RCTs offer the most methodologically rigorous approach to establishing cause and effect, thereby providing the highest quality evidence. A number of approaches have been used to grade the quality of evidence and the resulting strength of recommendations. ${ }^{26,27}$ The large number of systems for measuring the quality of evidence and recommendations is confusing ${ }^{28}$ and all approaches used previously for grading levels of evidence and the strength of recommendations have important shortcomings. ${ }^{15,26}$

Great progress has been made in obtaining reliable evidence on the beneficial effects of interventions, but developments in the identification, interpretation, and reporting of harmful effects is more challenging. ${ }^{29,30}$ The European Medicines Agency (EMEA) and the USA Food and Drug Administration (FDA) have clearly stated that RCTs are insufficient to assess the side effects of treatments largely because of their small size, and that post-marketing surveillance is needed to pick up rare events occurring in the at-risk population. There is a need to include evidence about harms (risks) in recommendations (Figure 1).

Shortcomings of RCTs are well known and include selection bias and concerns regarding external and internal validity. Thus, "real life" studies - conducted in the whole patient population without excluding many patients - are needed to support the recommendations based on RCTs.

More recently, the "Guidelines for WHO [World Health Organisation] guidelines" recommended using a specific, uniform grading system. ${ }^{31}$ The GRADE (Grading of Recommendations Assessment, Development and Evaluation) approach is one of the recommended systems ${ }^{27}$ and is being used increasingly by a number of organisations. ${ }^{32-37}$ It grades 
Table 1. Grading the strength of recommendations and quality of evidence in the ARIA guidelines according to the GRADE system.

\begin{tabular}{|c|c|c|c|c|}
\hline Notation* & $\begin{array}{l}\text { Strength of } \\
\text { recommendation and } \\
\text { quality of evidence }\end{array}$ & $\begin{array}{l}\text { Clarity of balance between } \\
\text { desirable and undesirable } \\
\text { effects }\end{array}$ & $\begin{array}{l}\text { Quality of supporting } \\
\text { evidence }\end{array}$ & Implications \\
\hline $1 \mathrm{~A}$ & $\begin{array}{l}\text { Strong recommendation } \\
\text { High-quality evidence }\end{array}$ & $\begin{array}{l}\text { Desirable effects clearly } \\
\text { outweigh undesirable effects, or } \\
\text { vice versa }\end{array}$ & $\begin{array}{l}\text { Consistent evidence from well- } \\
\text { performed RCTs or exceptionally } \\
\text { strong evidence from unbiased } \\
\text { observational studies. }\end{array}$ & $\begin{array}{l}\text { Recommendation can apply to most } \\
\text { patients in most circumstances. } \\
\text { Further research is unlikely to change our } \\
\text { confidence in the estimate of effect. }\end{array}$ \\
\hline $1 C$ & $\begin{array}{l}\text { Strong recommendation } \\
\text { Low-quality evidence }\end{array}$ & $\begin{array}{l}\text { Desirable effects clearly } \\
\text { outweigh undesirable effects, or } \\
\text { vice versa }\end{array}$ & $\begin{array}{l}\text { Evidence for at least one critical } \\
\text { outcome from RCTs with serious } \\
\text { flaws, observational studies, or } \\
\text { indirect evidence }\end{array}$ & $\begin{array}{l}\text { Recommendation may change when } \\
\text { higher quality evidence becomes } \\
\text { available. } \\
\text { Further research (if performed) is likely to } \\
\text { have an important impact on our } \\
\text { confidence in the estimate of effect and } \\
\text { is likely to change the estimate. }\end{array}$ \\
\hline $1 \mathrm{D}$ & $\begin{array}{l}\text { Strong recommendation } \\
\text { Very low-quality } \\
\text { evidence (very rarely } \\
\text { applicable) }\end{array}$ & $\begin{array}{l}\text { Desirable effects clearly } \\
\text { outweigh undesirable effects, or } \\
\text { vice versa }\end{array}$ & $\begin{array}{l}\text { Evidence for at least one of the } \\
\text { critical outcomes from } \\
\text { unsystematic clinical observation } \\
\text { or very indirect evidence }\end{array}$ & $\begin{array}{l}\text { Recommendation may change when } \\
\text { higher quality evidence becomes } \\
\text { available. } \\
\text { Any estimate of the effect for at least } \\
\text { one critical outcome is very uncertain. }\end{array}$ \\
\hline $2 \mathrm{~A}$ & $\begin{array}{l}\text { Weak recommendation } \\
\text { High-quality evidence }\end{array}$ & $\begin{array}{l}\text { Desirable effects closely balanced } \\
\text { with undesirable effects }\end{array}$ & $\begin{array}{l}\text { Consistent evidence from well- } \\
\text { performed RCTs or exceptionally } \\
\text { strong evidence from unbiased } \\
\text { observational studies }\end{array}$ & $\begin{array}{l}\text { The best action may differ depending on } \\
\text { circumstances or patients' or societal } \\
\text { views. } \\
\text { Further research is very unlikely to change } \\
\text { our confidence in the estimate of the } \\
\text { effect. }\end{array}$ \\
\hline $2 C$ & $\begin{array}{l}\text { Weak recommendation } \\
\text { Low-quality evidence }\end{array}$ & $\begin{array}{l}\text { Uncertainty in the estimates of } \\
\text { desirable and undesirable effects; } \\
\text { desirable effects may be closely } \\
\text { balanced with undesirable } \\
\text { effects }\end{array}$ & $\begin{array}{l}\text { Evidence for at least one critical } \\
\text { outcome from RCTs with serious } \\
\text { flaws, observational studies, or } \\
\text { indirect evidence }\end{array}$ & $\begin{array}{l}\text { Other alternatives may be equally } \\
\text { reasonable. } \\
\text { Further research is very likely to have } \\
\text { important impact on our confidence in } \\
\text { the estimate of effect and is likely to } \\
\text { change the estimate. }\end{array}$ \\
\hline $2 \mathrm{D}$ & $\begin{array}{l}\text { Weak recommendation } \\
\text { Very low-quality } \\
\text { evidence }\end{array}$ & $\begin{array}{l}\text { Major uncertainty in the } \\
\text { estimates of desirable and } \\
\text { undesirable effects; desirable } \\
\text { effects may be closely balanced } \\
\text { with undesirable effects }\end{array}$ & $\begin{array}{l}\text { Evidence for at least one critical } \\
\text { outcome from unsystematic } \\
\text { clinical observation or very } \\
\text { indirect evidence }\end{array}$ & $\begin{array}{l}\text { Other alternatives may be equally } \\
\text { reasonable. } \\
\text { Any estimate of the effect for at least } \\
\text { one critical outcome is very uncertain. }\end{array}$ \\
\hline $\begin{array}{l}\text { * Notation i } \\
\text { RCT - rando } \\
\text { Adapted fro }\end{array}$ & $\begin{array}{l}\text { not a part of GRADE system } \\
\text { mised controlled trial } \\
\text { n Schünemann et al. (27) an }\end{array}$ & ; it was adopted for the ARIA guidelin & e to simplify the presentation. & \\
\hline
\end{tabular}

recommendations into two levels - strong and weak - and quality evidence into four categories - high, moderate, low and very low. ${ }^{27,28}$ While the quality of evidence is one of the factors influencing the strength of a recommendation, this strength is also influenced by the balance between the benefits and harms, resource utilisation and patients' views ${ }^{3}$ (Tables 1 and 2). The GRADE approach is therefore closer to patients' needs than former grading systems based on RCT results. 
Table 2. Implications of strong and weak recommendations.

\begin{tabular}{lll} 
Implications & Strong recommendation & Weak recommendation \\
\hline For patients & $\begin{array}{l}\text { Most individuals in this situation would want the } \\
\text { recommended course of action and only a small } \\
\text { proportion would not. Formal decision aids are not } \\
\text { likely to be needed to help individuals make decisions } \\
\text { consistent with their values and preferences. }\end{array}$ & $\begin{array}{l}\text { The majority of individuals in this situation would want the } \\
\text { suggested course of action, but many would not. }\end{array}$ \\
\hline For clinicians & $\begin{array}{l}\text { Most individuals should receive the intervention. } \\
\text { Adherence to this recommendation according to the } \\
\text { guideline could be used as a quality criterion or } \\
\text { performance indicator. }\end{array}$ & $\begin{array}{l}\text { Recognise that different choices will be appropriate for different } \\
\text { patients, and that you must help each patient arrive at a } \\
\text { management decision consistent with her or his values and } \\
\text { preferences. Decision aids may well be useful helping individuals } \\
\text { making decisions consistent with their values and preferences. }\end{array}$ \\
\hline $\begin{array}{l}\text { For policy } \\
\text { makers }\end{array}$ & $\begin{array}{l}\text { The recommendation can be adapted as policy in } \\
\text { most situations }\end{array}$ & $\begin{array}{l}\text { Policy making will require substantial debates and involvement of } \\
\text { many stakeholders }\end{array}$ \\
\hline From Schünemann et al. (27) and Brozek et al (12) &
\end{tabular}

Table 3. Guidelines for allergic rhinitis.

\begin{tabular}{|c|c|c|c|c|c|c|c|}
\hline & $\begin{array}{l}\text { Year of } \\
\text { development }\end{array}$ & $\begin{array}{l}\text { Ref } \\
\text { no. }\end{array}$ & & Evidence model & \multicolumn{2}{|c|}{ Pocket guideRhiniti\$ } & classification \\
\hline International consensus & 1993-1994 & (4) & International & None & & & Seasonal-perennial \\
\hline Practice parameters & 1996-1997 & (5) & USA & None & & & Seasonal-perennial \\
\hline EAACI consensus & 1999 & (6) & Europe & None & & & Seasonal-perennial \\
\hline IPCRG & $2003-2006$ & (9) & International & $\begin{array}{l}\text { Royal College of } \\
\text { General Practionners (43) }\end{array}$ & & & Intermittent-persistent \\
\hline ARIA 2008 Update & $2006-2008$ & $(2)$ & International & Shekelle (38) & $(44)$ & & Intermittent-persistent \\
\hline $\mathrm{BSACI}$ & $2006-2008$ & (10) & UK & Shekelle (38) & & & Seasonal-perennial \\
\hline 2008 Practice parameters & $2006-2007$ & (11) & USA & Shekelle (38) & & & Seasonal-perennial \\
\hline
\end{tabular}

\section{Evolution of concepts in allergic rhinitis guidelines}

The first three guidelines for allergic rhinitis set the scene for evidence-based guidelines, although they were opinionbased. ${ }^{4-6}$ Two of them proposed a stepwise approach (Table 3).

The ARIA initiative ${ }^{8}$ was developed in collaboration with the WHO as a state-of-the-art guideline for the specialist as well as for the general practitioner (GP):

- To update their knowledge of allergic rhinitis.

- To highlight the impact of allergic rhinitis on asthma.

- To provide an evidence-based documented revision of diagnostic methods.

- To provide an evidence-based revision to treatments available in rhinitis.

- To set goals for treatment.

- To propose a stepwise approach to disease management for rhinitis and for rhinitis and asthma co-morbidities.

In the ARIA document, a new subdivision of allergic rhinitis was proposed, with patients categorised as having intermittent or persistent rhinitis (superseding the previous categories of seasonal and perennial). This classification is closer to patient needs and is easier for GPs to use. Most patients are polysensitised and different allergen exposures are superseded so that it is often difficult to differentiate seasonal and perennial symptoms. Moreover, many if not most patients allergic to indoor allergens have intermittent symptoms ${ }^{38}$ The severity of allergic rhinitis has been classified as "mild' and "moderate/severe" depending on the severity of symptoms and effect on quality of life defined by physical and social activities as well as school and work performance.

ARIA considered the treatment of patients with rhinitis based on previously published documents but offered for the first time an evidence-based documentation of recommendations. ${ }^{38}$ The management of allergic rhinitis included allergen avoidance (rarely effective), medications (pharmacological treatment), immunotherapy, and education. Depending on the category and severity of allergic rhinitis, a stepwise therapeutic approach was proposed. 
The International Primary Care Respiratory Group (IPCRG) Guideline on the management of rhinitis in primary care ${ }^{9}$ is fully consistent with the ARIA guidelines. It was developed as part of a set of several guidelines written by GPs specifically to aid the management of respiratory diseases in the primary care setting. ${ }^{39,40}$ It highlights the treatment goals and the classification of the condition according to symptom frequency (intermittent or persistent) and severity (mild or moderatesevere). It covers the need for allergen avoidance, pharmacologic therapy including immunotherapy, alternative therapies, management of ocular symptoms, the management of co-existing allergic rhinitis and asthma, and the need for follow-up and ongoing care for patients with rhinitis. ${ }^{9}$

The British Society of Allergy and Clinical Immunology (BSACl) guidelines for the management of patients with rhinitis are intended for use by any physician treating allergic conditions. ${ }^{10}$ Evidence for the recommendations was obtained by using electronic literature searches. Each article was reviewed for suitability for inclusion in the guideline. The recommendations were evidence-graded at the time of preparation of these guidelines and the grades of recommendation and levels of evidence are defined according to Shekelle. ${ }^{38}$ During the development of these guidelines, a web-based system was used to allow consultation with all $\mathrm{BSACl}$ members. The draft guidelines were amended by the Standards of Care Committee after careful consideration of all comments and suggestions. Where evidence was lacking, a consensus was reached among the experts on the committee.

The Practice Parameters for the diagnosis and management of allergic rhinitis from the American Academy of Allergy, Asthma and Immunology (AAAAl) and the American College of Allergy, Asthma and Immunology (ACAAI) have recently been published. ${ }^{11}$ This is an update of the previous document published in $1998^{41}$ using the model of evidence of Shekelle. ${ }^{38}$ They reviewed new medications available, combination therapy, the need to consider benefits versus safety and proposed a rhinitis action plan.

The ARIA 2009 Revision $^{12 a}$ is based on GRADE. Clinical questions covered by this document were developed in consultation with the ARIA guideline panel. The key questions can be summarised briefly as:

- Should allergen avoidance methods be used by parents to avoid development of allergy in children?

- Should occupational allergen avoidance methods be used?

- Should patients with allergic rhinitis and/or conjunctivitis use H1-antihistamines, glucocorticosteroids, antileukotrienes, chromones, decongestants, or ipratropium bromide? What is the relative effect of these medications?
- Should allergen specific immunotherapy be used in patients with allergic rhinitis? What is the effect of subcutaneous, intranasal, and sublingual specific immunotherapy?

- Should complementary and alternative treatments be used for allergic rhinitis?

- Should medications for the treatment of allergic rhinitis be used in patients with concomitant asthma for the treatment of asthma?

Some of the allergic rhinitis guidelines are reviewed in Table 3.

\section{Importance of guidelines for the management of allergic rhinitis}

Prior to their implementation, guidelines should be tested for their accuracy and user-friendliness. Unfortunately such a validation has not been performed for most guidelines. In allergic rhinitis, two studies have attempted to elicit whether a guideline-based treatment is more effective than free treatment choice. The International Consensus of Rhinitis ${ }^{4}$ was tested in patients with seasonal allergic rhinitis using a cluster-randomised trial. ' It was found that patients treated by primary care physicians using the recommended treatment had significantly improved quality-of-life and reduced symptoms compared to those treated by physicians who used free treatment choice. In another cluster-randomised trial, the ARIA guideline ${ }^{8}$ was tested in patients with persistent allergic rhinitis treated by specialists. It was found that the ARIAbased approach was more effective than free treatment choice. ${ }^{45}$ The results of these two studies support the recommendation to use guidelines for the treatment of allergic rhinitis, particularly in primary care.

\section{Use of rhinitis guidelines at the primary care level}

Primary care physicians treat the majority of patients with respiratory diseases. ${ }^{13,14}$ However, in primary care, guidelines for chronic respiratory diseases are not widely accepted, limitations reduce the use of some guidelines, and guidelines are insufficiently implemented for asthma ${ }^{46}$ or rhinitis. ${ }^{47}$ With the advent of rhinitis guidelines and the high prevalence of rhinitis seen in primary care settings, it is important to investigate the knowledge, attitudes, and practices of primary care physicians with regard to these guidelines. In allergic rhinitis, about half of the physicians in France claimed to know the ARIA guidelines and said they followed them, ${ }^{48}$ but current marketing studies show that a majority of GPs do not fully follow ARIA. In order to gain better acceptance of chronic respiratory diseases guidelines in primary care, there is a need for the development of guidelines with intense involvement of GPs. 
Some of the reasons why GPs do not always implement guidelines are: inadequate organisation in practice, ${ }^{49}$ scepticism about the effectiveness of guidelines; ${ }^{50}$ and/or the difficulty of GPs to cope with evidence-based medicine in day-to-day practice..$^{50}$ Since clinical management following evidence-based guidelines yields better results for patients, ${ }^{7,45}$ it is important to have access to primary care guidelines which are specifically relevant to, and provided by, primary care. The IPCRG asked primary care experts from several countries to develop primary care guidelines for the diagnosis and treatment of asthma, COPD and rhinitis. ${ }^{39}$ However, these guidelines were based on an evidence-based model mostly based on RCT evidence. The ARIA guidelines have always been developed with primary care physicians, ${ }^{2,8}$ and the recent ARIA 2008 pocket guide ${ }^{44}$ was developed with the World Organisation of primary care physicians (Wonca), the IPCRG, and the European Federation of Allergy and Airway Diseases Patients Association (EFA). The ARIA 2009 revision ${ }^{12 a}$ has also been developed with primary care physicians and members of patient organisations who actively participated in the recommendations.

The applicability of guidelines in primary care is not always clear. ${ }^{51}$ Whilst there is increasing agreement on the components of proper clinical practice guidelines and what constitutes high quality evidence, it is also clear that the highest quality evidence from RCTs is often based on highly selected patients not representing the population of patients seen in day-to-day practice. In a study carried out in general and specialist practices in Norway, only $5.4 \%$ of the study asthma patients met with the criteria of common RCTs carried out in asthma. ${ }^{25}$ Therefore, clinicians need to evaluate the generalisability or directness of such RCTs to a clinical population, how close the intervention is in general practice to that of the RCT, and how important or relevant the outcomes in the trial are for general practice patients. Therefore, detailed descriptions of these factors, ideally in concise evidence profiles and summaries, are required to allow clinicians' judgment about whether the evidence used for a recommendation is applicable to their practice.

Moreover, compliance with treatment, a major problem for allergy and asthma management, is far better in RCTs than in real life. Thus, "real life" or pragmatic trials are needed but are rarely available for allergic diseases. ${ }^{7.45}$ Furthermore, there is an urgent need to determine whether patients enrolled in allergic rhinitis RCTs are representative of the patient population seen in primary care.

The accurate diagnosis of rhinitis is essential in primary care. The IPCRG guideline on the diagnosis of respiratory diseases ${ }^{40}$ is clearly written, evidence-based, and will be of great help for the primary care physician. It is, however, not very easy to differentiate allergic rhinitis from rhinosinusitis ${ }^{52}$ or non-allergic rhinitis ${ }^{53}$ (see Figure 2).

As for any document, rhinitis guidelines need to be

Figure 2. Symptoms suggestive of a diagnosis of allergic rhinitis.

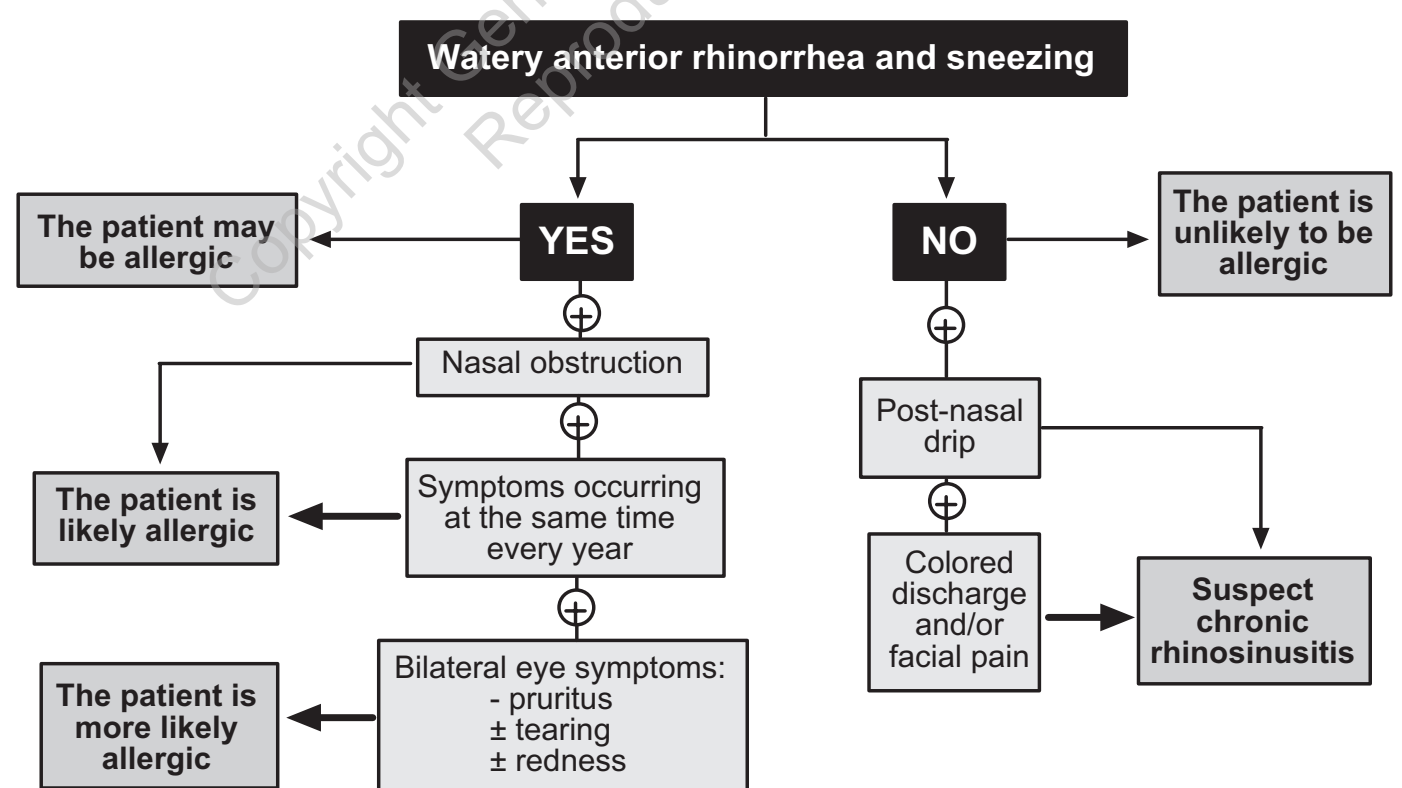

Confirm diagnosis of allergic rhinitis by skin tests and/or serum specific IgE
Confirm diagnosis of rhinosinusitis by ENT examination-CT scan

From ARIA 2008 update (2) 
continuously revised, mostly because the science and evidence concerning rhinitis is evolving rapidly and guidelines are based on published evidence. There is, however, a very clear need to perform high quality real life studies using, for example, cluster randomised designs to provide concrete evidence that the applicability of evidence obtained in scientifically conducted RCTs translates into daily practice.

\section{Summary}

Clinical Practice Guidelines for allergic rhinitis have been developed over the past 15 years and have been found to improve the management of patients with allergic rhinitis. They were based on various evidence-based models. ARIA (allergic rhinitis and its impact on asthma) was the first evidenced-based guideline, and the ARIA 2009 Revision is the first evidence-based guideline using GRADE methodology. ARIA was developed with primary care physicians who treat the majority of patients with allergic rhinitis.

\section{Conflict of interest}

None to declare.

\section{References}

1. Bousquet J, Khaltaev N. Global surveillance, prevention and control of Chronic Respiratory Diseases. A comprehensive approach. Global Alliance against Chronic Respiratory Diseases. World Health Organization. ISBN 978924 156346 8. 2007:148 pages.

2. Bousquet J, Khaltaev N, Cruz AA, et al. Allergic Rhinitis and its Impact on Asthma (ARIA) 2008 update (in collaboration with the World Health Organization, GA(2)LEN and AllerGen). Allergy 2008;63 Suppl 86:8-160.

3. Green RJ, Davis G, Price D. Concerns of patients with allergic rhinitis: the Allergic Rhinitis Care Programme in South Africa. Prim Care Resp J 2007;16(5):299-303. http://dx.doi.org/10.3132/pcrj.2007.00062

4. International Consensus Report on Diagnosis and Management of Rhinitis. International Rhinitis Management Working Group. Allergy 1994;49(19 Suppl):1-34.

5. Dykewicz MS, Fineman S, Skoner DP, et al. Diagnosis and management of rhinitis: complete guidelines of the Joint Task Force on Practice Parameters in Allergy, Asthma and Immunology. American Academy of Allergy, Asthma, and Immunology. Ann Allergy Asthma Immunol 1998;81(5 Pt 2):478-518.

6. Van-Cauwenberge $P, B a c h e r t ~ C$, Passalacqua $G$, et al. Consensus statement on the treatment of allergic rhinitis. EAACI Position paper. Allergy 2000;55:116-34.

7. Bousquet J, Lund VJ, Van Cauwenberge $P$, et al. Implementation of guidelines for seasonal allergic rhinitis: a randomized controlled trial. Allergy 2003;58(8):733-41. http://dx.doi.org/10.1034/j.1398-9995.2003.00076.x

8. Bousquet J, Van Cauwenberge P, Khaltaev N. Allergic rhinitis and its impact on asthma. J Allergy Clin Immunol 2001;108(5 Suppl):S147-334. http://dx.doi.org/10.1067/mai.2001.118891

9. Price D, Bond C, Bouchard J, et al. International Primary Care Respiratory Group (IPCRG) Guidelines: management of allergic rhinitis. Prim Care Resp J 2006;15(1):58-70. http://dx.doi.org/10.1016/j.pcrj.2005.11.002

10. Scadding GK, Durham SR, Mirakian R, et al. BSACl guidelines for the management of allergic and non-allergic rhinitis. Clin Exp Allergy 2008;38(1):19-42.

11. Wallace DV, Dykewicz MS, Bernstein DI, et al. The diagnosis and management of rhinitis: an updated practice parameter. J Allergy Clin Immunol 2008;122(2 Suppl):S1-84. http://dx.doi.org/10.1016/j.jaci.2008.06.003
12. Brozek JL, Baena-Cagnani CE, Bonini S, et al. Methodology for development of the Allergic Rhinitis and its Impact on Asthma guideline 2008 update. Allergy 2008;63(1):38-46.

12a. Schünemann H, Brozek J, Bousquet J, et al. ARIA 2009 Revision. Allergy 2009 (In press).

13. van Weel C. General practitioners' central role in management of asthma and allergic rhinitis. Allergy 2008;63(8):1005-07. http://dx.doi.org/10.1111/j.13989995.2008.01655.x

14. Ryan D, van Weel C, Bousquet J, et al. Primary care: the cornerstone of diagnosis of allergic rhinitis. Allergy 2008;63(8):981-9. http://dx.doi.org/10.1111/j.1398-9995.2008.01653.x

15. Bousquet J, Bieber T, Fokkens W, et al. Consensus statements, evidence-based medicine and guidelines in allergic diseases. Allergy 2008;63(1):1-4.

16. Bousquet J, Clark TJ, Hurd $S$, et al. GINA guidelines on asthma and beyond. Allergy 2007;62(2):102-12. http://dx.doi.org/10.1111/j.1398-9995.2006. 01305.x

17. Sackett $D L$, Rosenberg WM. The need for evidence-based medicine. J $R$ Soc Med 1995;88(11):620-4.

18. Elstein AS, Schwarz A. Clinical problem solving and diagnostic decision making: selective review of the cognitive literature. BMJ 2002;324(7339):729-32. http://dx.doi.org/10.1136/bmj.324.7339.729

19. Sackett DL, Rosenberg WM, Gray JA, Haynes RB, Richardson WS. Evidence based medicine: what it is and what it isn't [editorial]. BMJ 1996;312(7023):71-2.

20. Barton S. Which clinical studies provide the best evidence? The best RCT still trumps the best observational study. BMJ 2000;321(7256):255-6.

21. Petticrew M, Wilson P, Wright K, Song F. Quality of Cochrane reviews. Quality of Cochrane reviews is better than that of non-Cochrane reviews. BMJ 2002,324(7336):545.

22. Mulrow CD, Oxman AD. Cochrane Collaboration handbood. Cochrane Library, Issue 4. Oxford: Update Software; 1997.

23. Mant D. Can randomised trials inform clinical decisions about individual patients? Lancet 1999;353(9154):743-6. http://dx.doi.org/10.1016/S01406736(98)09102-8

24. Earle CC, Weeks JC. Evidence-based medicine: a cup half full or half empty? [editorial] [In Process Citation]. Am J Med 1999;106(2):263-4.

25. Herland K, Akselsen JP, Skjonsberg OH, Bjermer L. How representative are clinical study patients with asthma or COPD for a larger "real life" population of patients with obstructive lung disease? Respir Med 2005;99(1):11-19. http://dx.doi.org/10.1016/j.rmed.2004.03.026

26. Atkins D, Briss PA, Eccles M, et al. Systems for grading the quality of evidence and the strength of recommendations II: pilot study of a new system. BMC Health Serv Res 2005;5(1):25. http://dx.doi.org/10.1186/1472-6963-5-25

27. Schunemann HJ, Jaeschke R, Cook DJ, et al. An official ATS statement: grading the quality of evidence and strength of recommendations in ATS guidelines and recommendations. Am J Respir Crit Care Med 2006;174(5):605-14. http://dx.doi.org/10.1164/rccm.200602-197ST

28. Guyatt G, Vist G, Falck-Ytter $Y$, Kunz R, Magrini N, Schunemann H. An emerging consensus on grading recommendations. wwwevidencebasedmedicinecom. 2005;Module 37. Topic 2011:189.

29. Cuervo LG, Clarke M. Balancing benefits and harms in health care. BMJ 2003;327(7406):65-6. http://dx.doi.org/10.1136/bmj.327.7406.65

30. Ernst $\mathrm{E}$, Pittler $\mathrm{MH}$. Assessment of therapeutic safety in systematic reviews: literature review. BMJ 2001;323(7312):546. http://dx.doi.org/10.1136/ bmj.323.7312.546

31. Global Programme on Evidence for Health Policy. Guidelines for WHO Guidelines. EIP/GPE/EQC/2003.1. Geneva, World Health Organization; 2003. 2003.

32. Atkins $D$, Best $D$, Briss PA, et al. Grading quality of evidence and strength of recommendations. BMJ 2004;328(7454):1490. http://dx.doi.org/10.1136/ bmj.328.7454.1490 
33. Guyatt GH, Oxman AD, Kunz R, et al. Going from evidence to recommendations. BMJ 2008;336(7652):1049-51. http://dx.doi.org/ 10.1136/bmj.39493.646875.AE

34. Guyatt GH, Oxman AD, Kunz R, et al. Incorporating considerations of resources use into grading recommendations. BMJ 2008;336(7654):1170-3. http://dx.doi.org/10.1136/bmj.39504.506319.80

35. Guyatt GH, Oxman AD, Kunz R, Vist GE, Falck-Ytter Y, Schunemann HJ. What is "quality of evidence" and why is it important to clinicians? BMJ 2008;336(7651):995-8. http://dx.doi.org/10.1136/bmj.39490.551019.BE

36. Guyatt $G H$, Oxman $A D$, Vist GE, et al. GRADE: an emerging consensus on rating quality of evidence and strength of recommendations. BMJ 2008;336(7650):924-6. http://dx.doi.org/10.1136/bmj.39489.470347.AD

37. Schunemann HJ, Oxman AD, Brozek J, et al. Grading quality of evidence and strength of recommendations for diagnostic tests and strategies. BMJ 2008;336(7653):1106-10. http://dx.doi.org/10.1136/bmj.39500.677199.AE

38. Shekelle PG, Woolf SH, Eccles M, Grimshaw J. Clinical guidelines: developing guidelines. BMJ 1999;318(7183):593-6.

39. van Schayck $C P$, Levy $M L$, Stephenson $P$, Sheikh A. The IPCRG Guidelines: developing guidelines for managing chronic respiratory diseases in primary care. Prim Care Resp J 2006;15(1):1-4. http://dx.doi.org/ 10.1016/j.pcrj.2005.12.003

40. Levy ML, Fletcher M, Price DB, Hausen T, Halbert RJ, Yawn BP. International Primary Care Respiratory Group (IPCRG) Guidelines: diagnosis of respiratory diseases in primary care. Prim Care Resp J 2006;15(1):20-34. http://dx.doi.org/10.1016/j.pcrj.2005.10.004

41. Dykewicz MS, Fineman S. Executive Summary of Joint Task Force Practice Parameters on Diagnosis and Management of Rhinitis. Ann Allergy Asthma Immunol 1998;81(5 Pt 2):463-8.

42. ARIA in the pharmacy: management of allergic rhinitis symptoms in the pharmacy. Allergic rhinitis and its impact on asthma. Allergy 2004;59(4):37387. http://dx.doi.org/10.1111/j.1398-9995.2003.00468.x

43. Royal College of General Practitioners. The development and implementation of clinical guidelines. Report of the clinical guidelines working group. London.
1995.

44. Bousquet J, Reid J, van Weel C, et al. Allergic rhinitis management pocket reference 2008. Allergy 2008;63(8):990-6. http://dx.doi.org/10.1111/j.13989995.2008.01642.x

45. Bousquet J, Bodez T, Gehano P, et al. Implementation of guidelines for allergic rhinitis (ARIA) in specialist practices. A randomised pragmatic controlled trial. Int Arch Allergy Immunol 2009:in press.

46. Swartz MK, Banasiak NC, Meadows-Oliver M. Barriers to effective pediatric asthma care. J Pediatr Health Care 2005;19(2):71-9

47. Ryan D, Grant-Casey J, Scadding G, Pereira S, Pinnock H, Sheikh A. Management of allergic rhinitis in UK primary care: baseline audit. Prim Care Resp J 2005;14(4):204-09. http://dx.doi.org/10.1016/j.pcrj.2005.03.009

48. Demoly P, Concas V, Urbinelli R, Allaert FA. Spreading and impact of the World Health Organization's Allergic Rhinitis and its Impact on Asthma guidelines in everyday medical practice in France. Ernani survey. Clin Exp Allergy 2008;38(11):1803-07.

49. Wiener-Ogilvie S, Huby G, Pinnock H, Gillies J, Sheikh A. Practice organisational characteristics can impact on compliance with the BTS/SIGN asthma guideline: qualitative comparative case study in primary care. BMC Fam Pract 2008;9:32. http://dx.doi.org/10.1186/1471-2296-9-32

50. Carlsen B, Glenton C, Pope C. Thou shalt versus thou shalt not: a metasynthesis of GPs'attitudes to clinical practice guidelines. $\mathrm{Br} J$ Gen Pract 2007;57(545):971-8. http://dx.doi.org/10.3399/096016407782604820

51. Price $D$, Thomas $M$. Breaking new ground: challenging existing asthma guidelines. BMC Pulm Med 2006;6 Suppl 1:S6. http://dx.doi.org/ 10.1186/1471-2466-6-S1-S6

52. Thomas M, Yawn BP, Price D, Lund V, Mullol J, Fokkens W. EPOS Primary Care Guidelines: European Position Paper on the Primary Care Diagnosis and Management of Rhinosinusitis and Nasal Polyps 2007 - a summary. Prim Care Resp J 2008;17(2):79-89. http://dx.doi.org/10.3132/pcrj.2008.00029

53. Bousquet J, Fokkens $W$, Burney $P$, et al. Important research questions in allergy and related diseases: nonallergic rhinitis: a GA2LEN paper. Allergy 2008;63(7):842-53. http://dx.doi.org/10.1111/j.1398-9995.2008.01715.x

\section{Available online at http://www.thepcrj.org}

